\title{
Pressure and reciprocal rate transient analysis for finite-conductivity vertical fractured hydrocarbon wells under trilinear flow
}

\author{
Freddy Humberto Escobar ${ }^{1}\left[\right.$ [ $\cdot$ Fabio Andrés Pineda ${ }^{1} \cdot$ Daniel Suescún-Díaz $^{2}$
}

Received: 1 April 2021 / Accepted: 19 May 2021 / Published online: 22 June 2021

(c) The Author(s) 2021

\begin{abstract}
Hydraulic well fracturing has been an important practice for well stimulation along the history of the hydrocarbon industry. Therefore, accurate and practical assessment of the fracturing job should be of importance. Interpretation of well pressure and rate test data in vertical finite-conductivity fractured hydrocarbon wells by the TDS methodology and conventional analysis are presented in this paper. The accuracy and practicality of the developed equations are successfully tested with synthetical examples and a field case.
\end{abstract}

Keywords Fracture conductivity $\cdot$ Linear flow regime $\cdot$ Bilinear flow regime $\cdot$ Half-fracture length $\cdot T D S$ technique

$\begin{array}{ll}\text { Abbreviations } \\ C & \text { Wellbore storage bbl/psi } \\ B & \text { Oil volume factor bbl/STB } \\ C_{\mathrm{fD}} & \text { Dimensionless fracture conductivity } \\ c_{\mathrm{t}} & \text { Total system compressibility } \mathrm{ps}^{-1} \\ c_{\mathrm{ff}} & \text { Total fracture compressibility } \mathrm{psi}^{-1} \\ h & \text { Reservoir thickness } \mathrm{ft} \\ k & \text { Formation permeability md } \\ k_{\mathrm{f}} w_{\mathrm{f}} & \text { Fracture conductivity md-ft } \\ h & \text { Reservoir thickness ft } \\ P & \text { Pressure psi } \\ P_{i} & \text { Initial reservoir pressure psi } \\ q & \text { Oil flow rate BPD } \\ q_{s c} & \text { Gas flow rate Mscf/D } \\ m(P) & \text { Pseudopressure psi }{ }^{2} / \mathrm{cp} \\ m & \text { Slope } \\ \bar{P}_{w s}(s) & \text { Laplacian pressure } \\ S & \text { Laplace parameter } \\ S_{m} & \text { Mechanical skin factor } \\ S_{m}, & \text { Apparent mechanical skin factor } \\ T & \text { Temperature }{ }^{\circ} \mathrm{R} \\ T & \text { Drawdown time hr } \\ t_{p} & \text { Production time hr }\end{array}$

Freddy Humberto Escobar fescobar@usco.edu.co

1 Department of Petroleum Engineering, Universidad Surcolombiana, Neiva, Huila, Colombia

2 Departamento de Ciencias Naturales, Universidad Surcolombiana, Avenida Pastrana, Neiva, Huila, Colombia
$\Delta t$

$t_{D}$

$t_{D} * P_{D}$

$t * \Delta P$

$t^{*} \Delta m(P)$

$t_{D}^{*}\left(1 / q_{D}\right)$

$t^{*}(1 / q)$

$\left(1 / q_{g}\right)^{\prime} x_{\mathrm{f}}$

Greeks

$\Delta$

$\phi$

$\eta$

$\mu$

\section{Suffices}

BL

BLRi

D

Dxf

$\mathrm{f}$

g

i

L

LBLi

LUSi

LRi

r

sc

US

USBLi
Buildup time hr

Dimensionless time

Dimensionless pressure derivative

Pressure derivative psi

Pseudopressure derivative $\mathrm{psi}^{2} / \mathrm{cp}$

Dimensionless reciprocal rate derivative

Reciprocal rate derivative 1/BPD for oil or D/

Mscf for gas

Half-fracture length $\mathrm{ft}$

\author{
Change drop \\ Porosity fraction \\ Diffusivity constant \\ Viscosity cp
}

Bilinear flow regime

Bilinear-radial intercept

Dimensionless

Dimensionless based on half-fracture length

Fracture

Gas

Initial

Linear flow regime

Linear bilinear intersection

Linear unit slope intersection

Linear radial intersection

Radial

Standard conditions

Unit slope

Unit slope bilinear intersection 


$\begin{array}{ll}\text { USRi } & \text { Unit slope radial intersection } \\ \text { wf } & \text { Well flowing } \\ \text { ws } & \text { Well static }\end{array}$

\section{Introduction}

Hydraulic fracturing is a very common way to stimulate hydrocarbon wells. Also, well test analysis is the most used practice to evaluate the results of a fracturing job. Well test analysis is mostly based upon analytical solutions which allow us to understand the formation and well flow dynamics. For well pressure tests, analytical models can be grouped into two types according to their solution: semianalytic models and asymptotic analytical models. A semianalytic model was first developed by Gringarten, Ramey and Raghavan (1974) for hydraulically fractured wells with fractures of infinite conductivity, and later, this semi-analytic model was adapted for hydraulically fractured wells with finite-conductivity fractures by Cinco-Ley, Samaniego and Dominguez (1978). They developed a mathematical model to study transient behavior in wells with vertical finite-conductivity fractures for dimensional times greater than 0.001 , which may be correlated with the dimensional finite conductivity of fractures. Their provided a type-curve matching interpretation technique.

Subsequently, Cinco-Ley and Samaniego (1981) developed an asymptotic analytical solution for the interpretation of transient pressure data for wells intercepted by a vertical fracture. With this, they demonstrated that for dimensional fracture conductivity less than 300 , the fracture conductivity cannot be considered as infinite. They also provided type curves for the determination of the reservoir and fracture parameters.

Later, Cinco-Ley (1982) developed a method for fractured wells considering different flow geometries. This work recognized that wells intercepted by a fracture had different flow behaviors than non-fractured wells, and application of traditional pressure analysis methods based upon radial flow theory, could yield erroneous results. His method was based on the bilinear flow rate, which is present when the linear flow of the fracture and the linear flow within the formation occur simultaneously.

Several other models were also introduced. For instance, Cossio, Moridis, and Blasingame (2013) presented a semianalytic solution for a finite-conductivity fractured using fractal geometry theory. Wong, Harrington and CincoLey (1984) presented a mathematical solution for pressure behavior under pseudolinear conditions which has useful applications when the fracture has a skin factor that allows having a linear flow from the fracture tip to the well.

As a final flow model mention, there are more, Lee and Brockenbrough (1986) introduced a new analytical solution, based on a trilinear flow model as shown in Fig. 1. This sketch shows how three linear flows make up the trilinear flow model. Flow in region 1 renders the fracture with a dominant flow in the $x$ direction. If the fracture is considered as a bending line, the flow in region 2 will be controlled by the $y$ direction. With similar reasoning, the flow in region 3 would be approximate in the $x$ direction for a very short period. These reasoning of flow behavior is reasonable for fluid flow before the pseudoradial flow regime shows up. In addition to the formulation of their trilinear flow model, they also conducted a study comparing this trilinear flow solution with that proposed by CincoLey et al. (1981). They found that the trilinear model fits perfectly with the model proposed by Cinco-Ley et al. (1981) up to a value of $t_{D}=1.0$. After this value, the deviation becomes more appreciable.

The authors are focused on well test interpretation by the TDS Technique, Tiab (1995), which is a novel, accurate and revolutionary methodology based upon characteristic points and lines found on the pressure and pressure derivative versus time $\log -\log$ plot -also to the reciprocal rate and reciprocal rate derivative versus time $\log -\log$ plot. Details of this technique is widely exposed on the textbooks of Escobar $(2015,2019)$ and a very comprehensive state-of-the-art is presented by Escobar, Jongkittnarukorn and Hernandez (2018). Classical articles on the TDS Technique for hydraulic fracture wells are presented by Tiab (1994) and Tiab et al (1999). Also, Escobar, Gonzalez and Hernandez (2016) extended the TDS Technique for well test interpretation under pseudolinear conditions using the already mentioned model by Wong et al (1984).

In this work, TDS Technique and straight-line conventional analysis are extended for the practical test data interpretation of finite-conductivity vertical fractured wells in hydrocarbons reservoirs using the trilinear flow model of Lee and Brockenbrough (1986). Both pressure transient and rate transient analysis are provided for the TDS Technique and conventional analysis, as well. The proposed equations were successfully tested with synthetic and actual field data.

\section{Mathematical formulation}

Lee and Brockenbrough (1986) provided a Laplace space pressure solution of a vertical fractured well where the flow is dominated by trilinear flow regime,

$\bar{P}_{w D}(s)=\frac{b}{s\left[s b C_{D}-\psi \tanh \psi\right]}$

where;

$a \equiv \frac{2}{C_{f D}} ; \quad b \equiv \frac{\pi}{C_{f D}}$ 
Fig. 1 A quadrant of the top view of the fractured well system and trilinear flow approximation. Taken from Lee and Brockenbrough (1986)

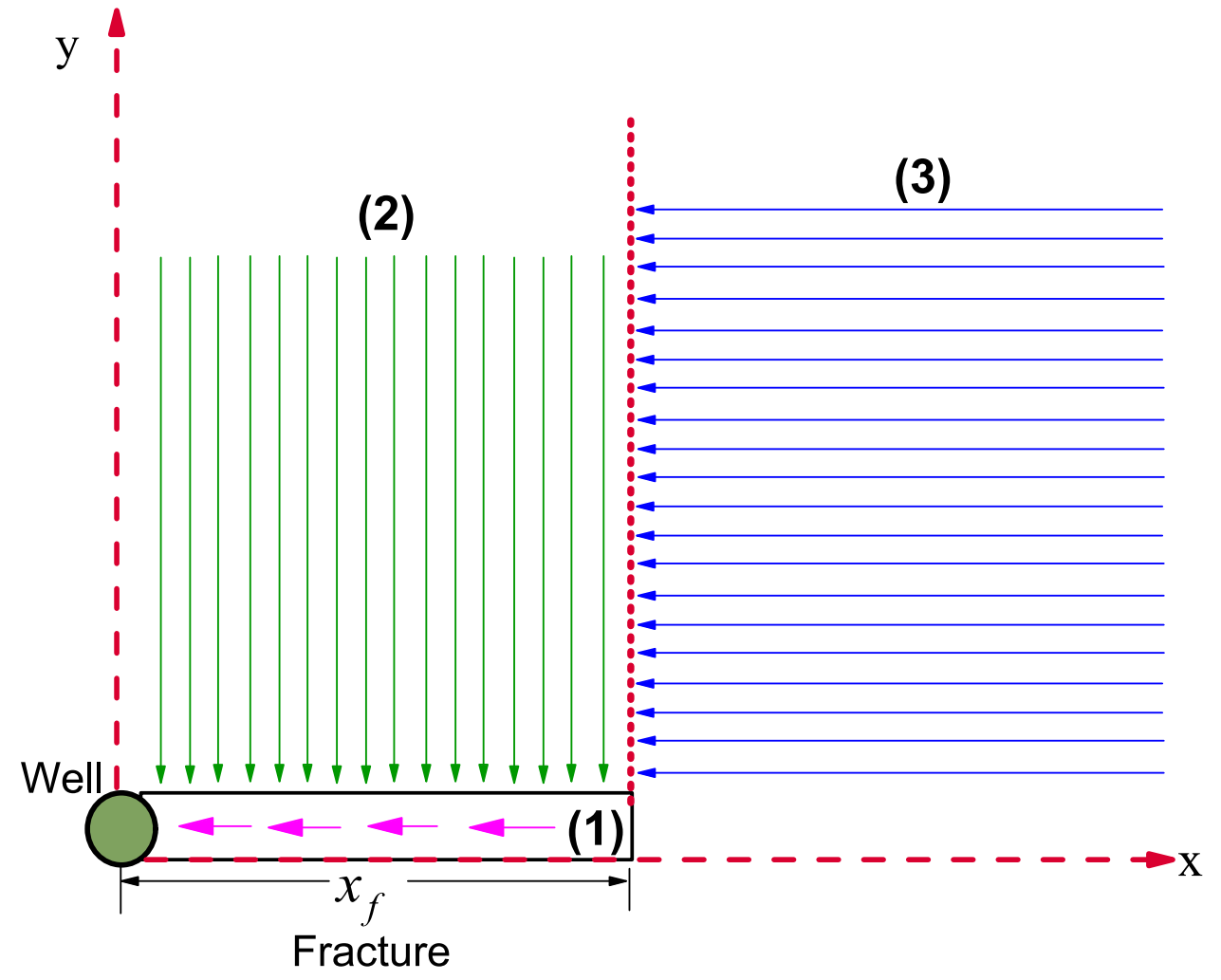

$\psi=\sqrt{\frac{a(s+\sqrt{s})}{1+\sqrt{(s+\sqrt{s})} S}+\frac{s}{\eta_{f}}}$

$\frac{1}{\eta_{f}}=\frac{k \phi_{f} c_{t f}}{k_{f} \phi c_{t}}$

The dimensionless quantities are defined below as:

$$
\begin{aligned}
& C_{D}=\frac{0.894 C}{\phi c_{t} h x_{f}^{2}} \\
& C_{f D}=\frac{k_{f} w_{f}}{k x_{f}}
\end{aligned}
$$

The dimensionless parameters for an oil reservoir are given below:

$$
\begin{gathered}
t_{D x_{f}}=\frac{0.0002637 k t}{\phi \mu c_{t} x_{f}^{2}} \\
P_{D}=\frac{k h\left(P_{i}-P_{w f}\right)}{141.2 q \mu B}
\end{gathered}
$$

The solution of the flow equation for the constant-pressure case;

$\bar{q}_{D}(s)=\frac{1}{s^{2} \bar{P}_{w D}(s)}$

Then, the dimensionless parameters are given by:

$\frac{1}{q_{D}}=\frac{k h\left(P_{i}-P_{w f}\right)}{141.2 q \mu B}$

$t_{D} *\left(1 / q_{D}\right)^{\prime}=\frac{k h \Delta P}{141.2 \mu B}\left[t *(1 / q)^{\prime}\right]$

The dimensionless quantities for gas reservoirs, constantrate case, are given as follows:

$t_{D x_{f}}=\frac{0.0002637 k t}{\phi\left(\mu c_{t}\right)_{i} x_{f}^{2}}$

$m(P)_{D}=\frac{k h\left[m\left(P_{i}\right)-m\left(P_{w f}\right)\right]}{1424.26 q_{s c} T}$ 
$t_{D} * m(P)_{D}^{\prime}=\frac{k h\left[t * \Delta m(P)^{\prime}\right]}{1424.26 T q_{s c}}$

The dimensionless parameters for the constant-pressure case, which are used in transient rate analysis, are provided below:

$\frac{1}{q_{D}}=\frac{k h\left[m\left(P_{i}\right)-m\left(P_{w f}\right)\right]}{1424.26 T} \frac{1}{q_{g}}$

$\left[t_{D} *\left(1 / q_{D}\right)^{\prime}\right]=\frac{k h[\Delta m(P)]}{1424.26 T}\left[t *(1 / q)^{\prime}\right]$

\section{Wellbore rate and pressure behavior}

Both dimensionless pressure and dimensionless pressure derivative versus dimensionless time behavior provided in Fig. 2 was generated with Eq. 1 while the reciprocal rate and reciprocal rate derivative behavior was obtained by using Eq. 10. In both cases the transient behaviors are about the same. As indicated in both plots, at early time the linear flow regime dominates the test. This is followed by a unit-slope tendency observed on both derivatives, although is shorter for the reciprocal rate case and finally a bilinear flow regime is developed. During the intermediate time when reciprocal rate derivative displays a unit-slope behavior, see Fig. 3,
Fig. 2 Log- $\log$ plot of dimensionless pressure and dimensionless pressure derivative versus dimensionless time for different dimensionless conductivities

Fig. 3 Log-log plot of dimensionless reciprocal rate and dimensionless reciprocal rate derivative versus dimensionless time for different dimensionless conductivities
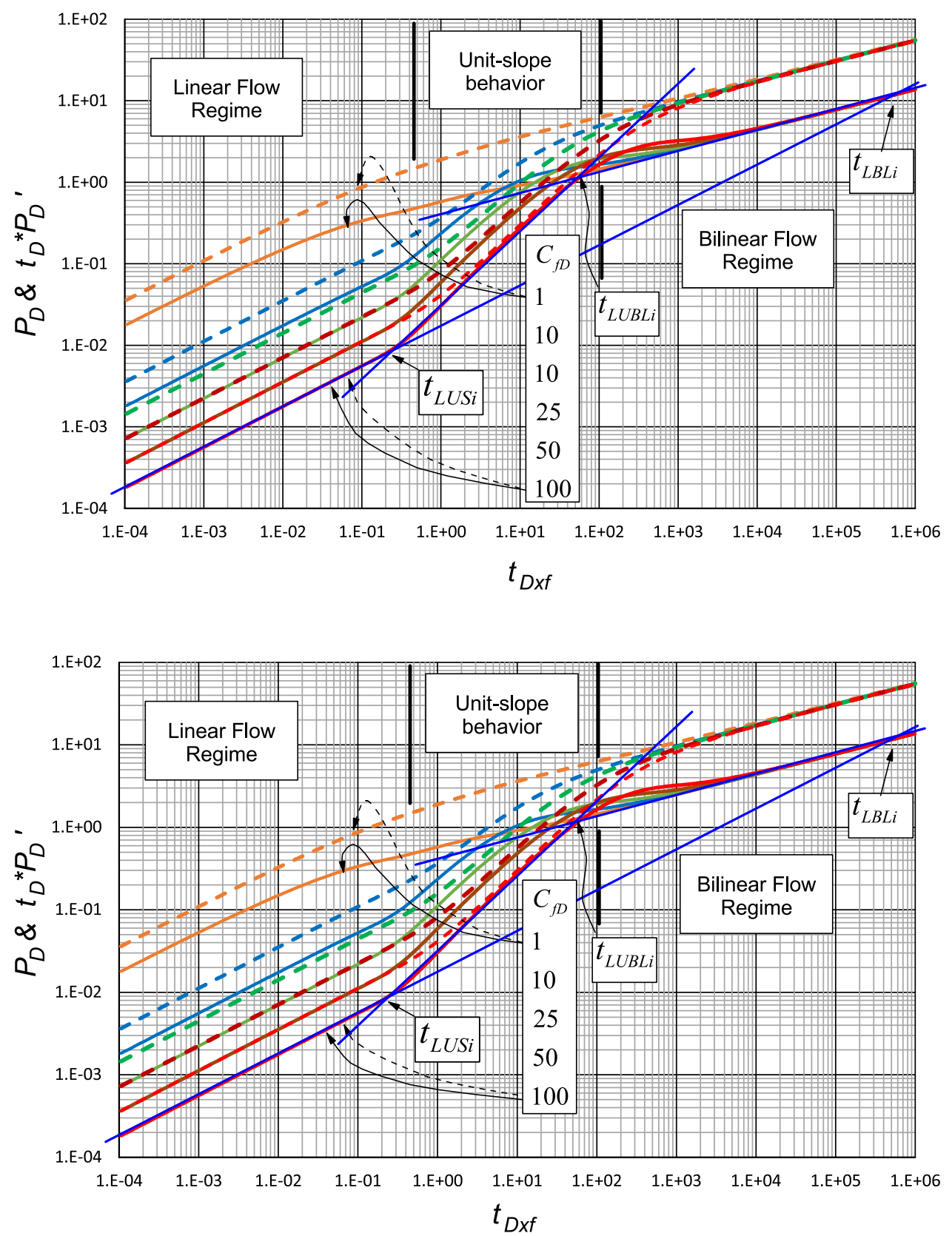
the reciprocal rate does not display a unit-slope behavior but a variety of slopes going to values higher than 2 . This, therefore, difficult the application of conventional analysis.

For a better understanding of the flow dynamics let us refer to Fig. 1 which sketches the trilinear model proposed by Lee and Brockenbrough (1986). They consider three flow zone. The first zone provides the pressure response of the fracture. The second zone is responsible for the simultaneous answer of two linear flows: one occurring inside the fracture and the other one from the formation to the fracture. Finally, region 3 consists of linear flow to the well-fracture system. As reflected in both pressure derivative and reciprocal rate derivative, the first flow regime occurs corresponds to a linear flow from formation to fracture. This means that the flow inside the fracture is imperceptible. It looks that the unit-slope behavior results from the transition between the early linear flow regime to the subsequent bilinear flow regime which takes place at later time. This bilinear flow may be formed by the simultaneous flow regime from the formation to the fracture and from zone 3 to the fracturewell system.

\section{Pressure transient analysis by the TDS technique for oil reservoirs}

TDS Technique, Tiab (1995), is a methodology based upon finding unique characteristic and points on the pressure and pressure derivative versus time log-log plot (this is extended to reciprocal rate and reciprocal rate derivative). Escobar $(2015,2019)$ presented two textbooks which clearly illustrate this technique.

For extension of the TDS Technique is necessary to find unified pressure/rate and pressure/reciprocal rate derivative behaviors so unique equations can be developed. For instance, Fig. 4 presents a unified behavior of the pressure derivative multiplied by the dimensionless fracture conductivity. The following equation is.

then obtained:

$\left(t_{D} * P_{D}^{\prime}\right)_{L} C_{f D}=0.6 \pi\left(t_{D}\right)_{L}^{0.5}$

Suffix $L$ in Eq. (18) stands for "Linear". Plugging Eqs. (6), (7) and (9) into Eq. (18) and solving for the fracture conductivity, it yields:

$k_{f} w_{f}=\frac{4.3 q \mu B}{h\left(t * \Delta P^{\prime}\right)_{L}} \sqrt{\frac{k t_{L}}{\phi \mu c_{t}}}$

Integration of Eq. (18) leads to find the governing pressure equation:

$\left(P_{D}\right)_{L}=\frac{0.6 \pi\left(t_{D}\right)_{L}^{0.5}}{0.5 C_{f D}}+c$

where $c$ is a given constant of no interest for this work. Again, replacing Eqs. (6, 7 and 8) into Eq. (20), another equation is found to find the fracture conductivity.

$k_{f} w_{f}=\frac{8.6 q \mu B}{h(\Delta P)_{L}} \sqrt{\frac{k t_{L}}{\phi \mu c_{t}}}$

Another unified behavior is found during the unit-slope behavior as shown in Fig. 5. The following expression governs such behavior:
Fig. 4 Unified pressure derivative times dimensionless conductivity versus dimensionless time during early linear flow regime

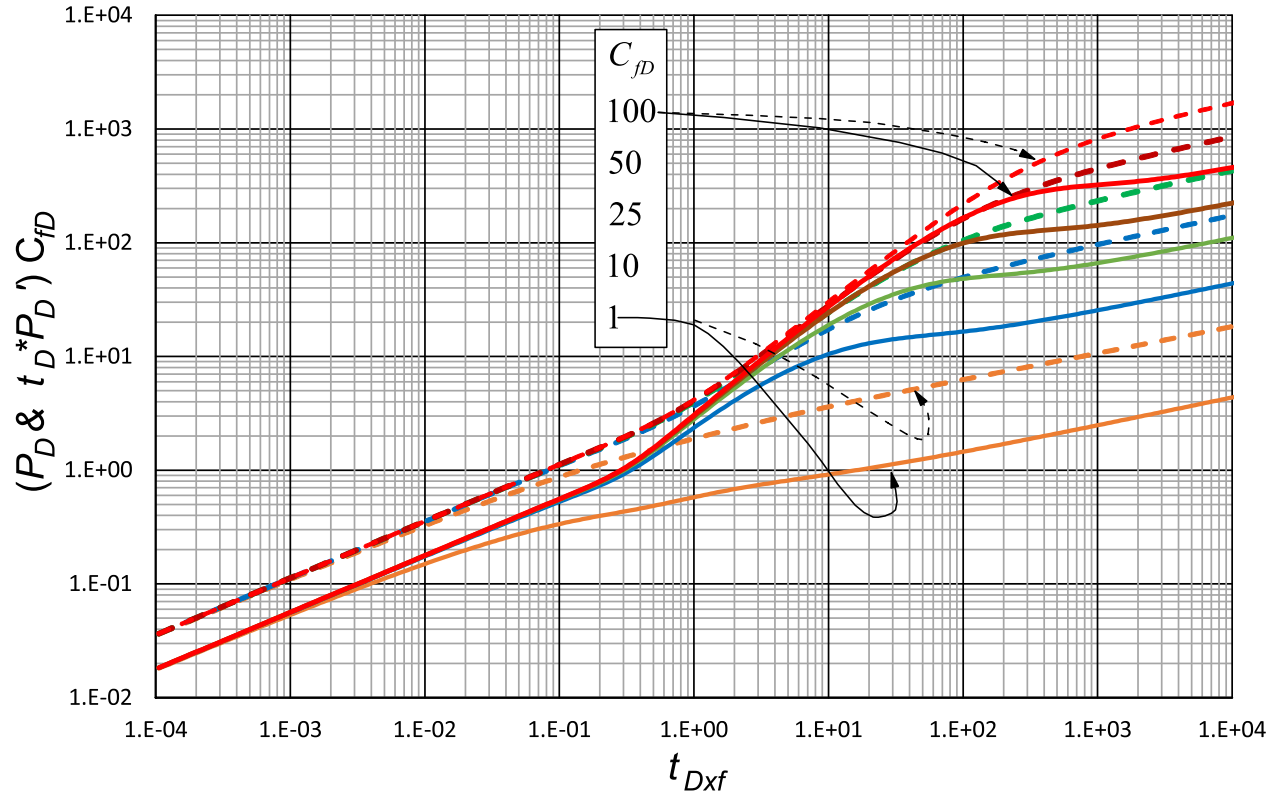


Fig. 5 Unified pressure derivative times dimensionless conductivity versus dimensionless time during the unit-slope flow behavior

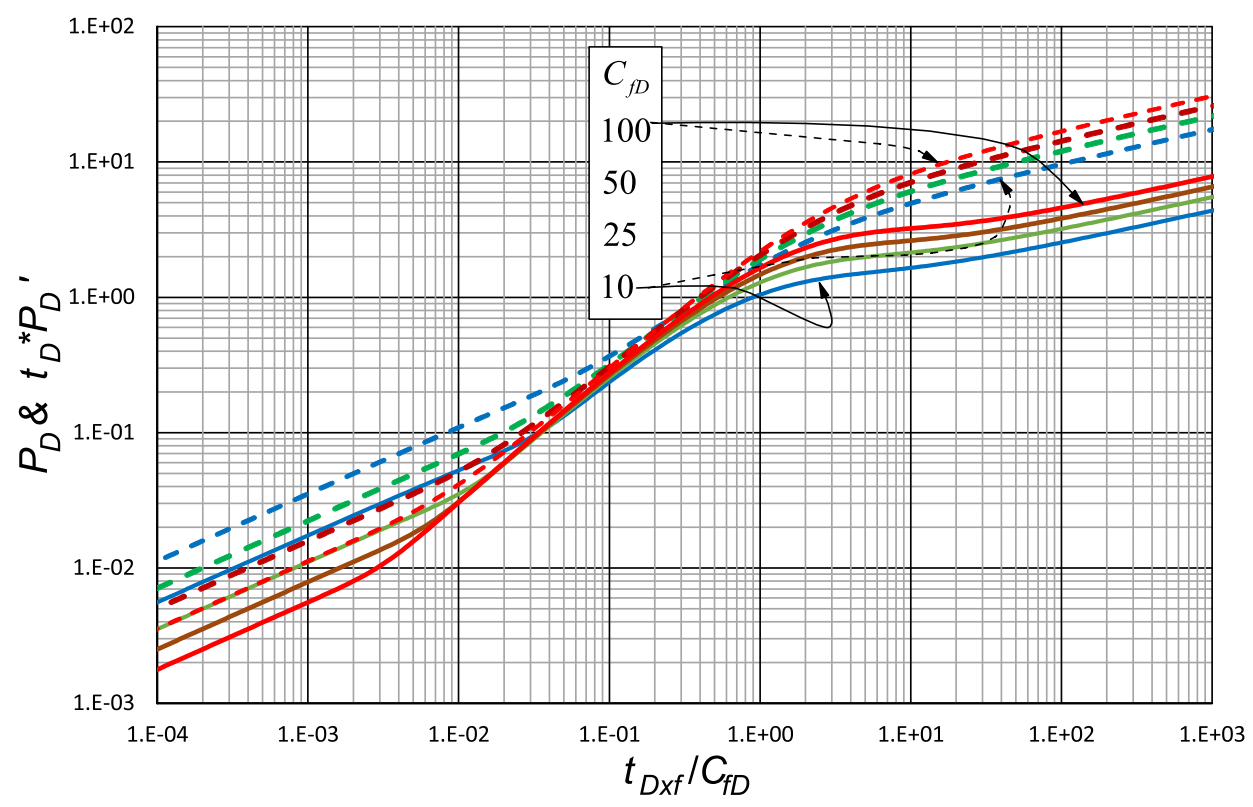

$\left(t_{D} * P_{D}^{\prime}\right)_{\mathrm{US}}=0.9 \pi \frac{\left(t_{D}\right)_{\mathrm{US}}}{C_{f D}}$

Again, we found by integration that the unified dimensionless pressure equation is governed by:

$\left(P_{D}\right)_{\mathrm{US}}=0.9 \pi \frac{\left(t_{D}\right)_{\mathrm{US}}}{C_{f D}}$

Replacement of the dimensionless quantities given by Eqs. 7, 8, 9 into Eqs. (22) and (23) allows to find two expressions for the determination of the half-fracture length:

$x_{f}=\frac{0.1 q B k}{h \phi c_{t} k_{f} w_{f}}\left(\frac{t_{\mathrm{US}}}{\left(t * \Delta P^{\prime}\right)_{\mathrm{US}}}\right)$

$x_{f}=\frac{0.1 q B k}{h \phi c_{t} k_{f} w_{f}}\left(\frac{t}{\Delta P}\right)_{\mathrm{US}}$

As seen in Fig. 2 a unified behavior exists by itself during linear flow regime. The pressure and pressure derivative governing equations during the bilinear flow regime are found to be:

$\left(t_{D} * P_{D}^{\prime}\right)_{L}=0.43414\left(t_{\mathrm{Dxf}}^{0.25}\right)_{L}$

$\left(P_{D}\right)_{B L}=1.736554\left(t_{D x f}^{0.25}\right)_{B L}$

Replacing the dimensionless parameters in the above equations, it yields: $x_{f}=60.254\left(\frac{q \mu B}{\mathrm{kh}\left(t * \Delta P^{\prime}\right)_{\mathrm{BL}}}\right)^{2} \sqrt{\frac{\mathrm{kt}_{\mathrm{BL}}}{\phi \mu c_{t}}}$

$x_{f}=976.35\left(\frac{q \mu B}{\mathrm{kh}(\Delta P)_{\mathrm{BL}}}\right)^{2} \sqrt{\frac{k t_{\mathrm{BL}}}{\phi \mu c_{t}}}$

We may also solve for formation permeability,

$k=15.3694\left(\frac{q \mu B}{h\left(t * \Delta P^{\prime}\right)_{\mathrm{BL}}}\right)^{4 / 3}\left(\frac{t_{\mathrm{BL}}}{\phi \mu c_{t} x_{f}^{2}}\right)^{1 / 3}$

$k=98.417\left(\frac{q \mu B}{h(\Delta P)_{\mathrm{BL}}}\right)^{4 / 3}\left(\frac{t_{\mathrm{BL}}}{\phi \mu c_{t} x_{f}^{2}}\right)^{1 / 3}$

\section{Pressure transient analysis by the conventional method for oil reservoirs}

Once the dimensionless parameters are replaced in Eq. 20, the following is obtained:

$\Delta P=P_{i}-P_{\mathrm{wf}}=\frac{8.6 q \mu B}{h k_{f} w_{f}} \sqrt{\frac{k}{\phi \mu c_{t}}} \sqrt{t}$

Which can be expressed as:

$P_{\mathrm{wf}}=P_{i}-m_{L} \sqrt{t}$ 
The above implies that a Cartesian plot of $\Delta P=\left(P_{i}-P_{\text {ws }}\right)$ vs. $t^{0.5} \quad$ (for d rawdown) or $\Delta P=\left(P_{\mathrm{ws}}-P_{\mathrm{wf}}\right)$ vs. $\left[\left(t_{p}+\Delta t\right)^{0.5}-\Delta t^{0.5}\right]$ (for buildup) yields a straight line which slope, $m_{L}$, provides the fracture conductivity. Such slope, $m_{L}$ is given by:

$m_{L}=\frac{8.6 q \mu B}{h k_{f} w_{f}} \sqrt{\frac{k}{\phi \mu c_{t}}}$

From which;

$k_{f} w_{f}=\frac{8.6 q \mu B}{\mathrm{hm}_{L}} \sqrt{\frac{k}{\phi \mu c_{t}}}$

The unit-slope pressure equation obtained from Eq. 23 allows finding:

$$
\begin{aligned}
& P_{\mathrm{wf}}=P_{i}-\frac{0.1 q \mathrm{Bk}}{h \phi c_{t} k_{f} w_{f}} t \\
& x_{f}=\frac{0.1 q \mathrm{Bk}}{h \phi c_{t} k_{f} w_{f}}\left(\frac{t}{\Delta P}\right)_{\mathrm{US}}
\end{aligned}
$$

Which can be expressed as:

$P_{\mathrm{wf}}=P_{i}-m_{\mathrm{US}} t$

A Cartesian plot of $\Delta P$ vs. $t$ yields a straight line which slope, $m_{U S}$, provides the half-fracture length. This slope is given by:

$m_{\mathrm{US}}=\frac{0.1 q \mathrm{Bk}}{h \phi c_{t} k_{f} w_{f} x_{f}}$

From which;

$x_{f}=\frac{0.1 q B k}{h \phi c_{t} k_{f} w_{f} m_{U S}}$

The bilinear pressure behavior obtained from Eq. 27 allows to develop:

$P_{\mathrm{wf}}=P_{i}-31.247 \frac{q \mu B}{\mathrm{kh}} \sqrt[4]{\frac{k}{\phi \mu c_{t} x_{f}^{2}}} \sqrt[4]{t}$

Which can be expressed as:

$P_{\mathrm{wf}}=P_{i}-m_{\mathrm{BL}} \sqrt[4]{t}$

Which implies that a Cartesian plot of $\Delta P=\left(P_{\mathrm{ws}}-P_{\mathrm{wf}}\right)$ vs. $\left[\left(t_{p}+\Delta t\right)^{0.25}-\Delta t^{0.25}\right]$ (for drawdown $)$ or $\Delta P=\left(P_{\mathrm{ws}}-P_{\mathrm{wf}}\right)$ vs. $\left[\left(t_{p}+\Delta t\right)^{0.25}-\Delta t^{0.25}\right]$ (for buildup) provides a straight line which slope, $m_{B L}$, provides the half-fracture length: $x_{f}=976.35\left(\frac{q \mu B}{\mathrm{kh}}\right)^{2} \sqrt{\frac{k}{\phi \mu c_{t}}}$

\section{Pressure transient analysis by the TDS technique for gas reservoirs}

Equations 18 and 20, 22 and 23 and 26 and 27 apply to gas reservoirs. Dimensionless pressure and dimensionless pressure derivative are changed by dimensionless pseudopressure and dimensionless pseudopressure derivative. Then, after replacing the dimensionless time expression given by Eq. 13 and the dimensionless pseudopressure and pseudopressure derivative given by Eqs. 14 and 15 in the abovementioned equations, it yields:

$k_{f} w_{f}=\frac{43.594 q_{\mathrm{sc}} T}{\mathrm{kh}\left[t * \Delta m(P)^{\prime}\right]} \sqrt{\frac{\mathrm{kt}_{L}}{\phi\left(\mu c_{t}\right)_{i}}}$

$k_{f} w_{f}=\frac{87.2 q_{\mathrm{sc}} T}{h[\Delta m(P)]_{L}} \sqrt{\frac{\mathrm{kt}_{L}}{\phi \mu c_{t}}}$

$x_{f}=\frac{1.062 q_{\mathrm{sc}} k T}{\phi \mu c_{t} \mathrm{hk}_{f} w_{f}}\left[\frac{t}{t * \Delta m(P)^{\prime}}\right]_{U S}$

$x_{f}=\frac{1.062 q_{\mathrm{sc}} k T}{\phi \mu c_{t} \mathrm{hk}_{f} w_{f}}\left[\frac{t}{\Delta m(P)}\right]_{\mathrm{US}}$

$x_{f}=6208.565\left(\frac{q T}{k h\left[t * \Delta m\left(P^{\prime}\right)\right]_{\mathrm{BL}}}\right)^{2} \sqrt{\frac{k t_{\mathrm{BL}}}{\phi\left(\mu c_{t}\right)_{i}}}$

$k=337.8\left(\frac{q T}{h\left[t * \Delta m\left(P^{\prime}\right)\right]_{\mathrm{BL}}}\right)^{4 / 3}\left(\frac{t_{\mathrm{BL}}}{\phi\left(\mu c_{t}\right)_{i} x_{f}^{2}}\right)^{1 / 3}$

$x_{f}=6208.565\left(\frac{q T}{\operatorname{kh}\left[t * \Delta m\left(P^{\prime}\right)\right]_{B L}}\right)^{2} \sqrt{\frac{k t_{\mathrm{BL}}}{\phi\left(\mu c_{t}\right)_{i}}}$

$k=2144.915\left(\frac{q T}{h[\Delta m(P)]_{\mathrm{BL}}}\right)^{4 / 3}\left(\frac{t_{\mathrm{BL}}}{\phi\left(\mu c_{t}\right)_{i} x_{f}^{2}}\right)^{1 / 3}$

The points of intersection between the different pressure derivative equations are very important for the verification of the reservoir parameters. These developed expressions are valid for both oil and gas cases, with the exception that for gas case the product of compressibility and viscosity is given at initial conditions. Thereby, the intersection points 
between Eqs. 18 and 22, 18 and 27, 22 and 27 and 11 and 27 provides the following expressions:

$x_{f}=\frac{1}{41.054} \sqrt{\frac{k t_{L U S i}}{\phi \mu c_{t}}}$

$k=1.606 \sqrt[5]{\frac{\phi \mu c_{t}\left(k_{f} w_{f}\right)^{4}}{x_{f}^{2} t_{L B L i}}}$

$k=11.7166 \sqrt[7]{\left(\frac{\phi \mu c_{t}}{t_{U S B L i}}\right)^{3} x_{f}^{2}\left(k_{f} w_{f}\right)^{4}}$

$k=\frac{670.606 \phi \mu c_{t} k_{f} w_{f} x_{f}}{t_{U S R i}}$

If radial flow is seen, Tiab (1995) found that during the radial flow regime the pressure derivative is governed by the following simple equation:

$\left(t_{D} * P_{D}^{\prime}\right)_{r}=0.5$

Then, the intersection between Eqs. 18, 22 and 27 with Eq. 53 yields the following:

$k=6.438 \sqrt[3]{\frac{\phi \mu c_{t}\left(k_{f} w_{f}\right)^{2}}{t_{L R i}}}$ $k=\frac{670.606 \phi \mu c_{t} k_{f} w_{f} x_{f}}{t_{U S R i}}$

$x_{f}=\frac{1}{81.6822} \sqrt{\frac{k t_{B L R i}}{\phi \mu c_{t}}}$

\section{Transient rate analysis by the TDS technique for oil reservoirs}

As shown in Fig. 6, the unified reciprocal rate derivative behavior obeys the following equation:

$\left[t_{D} *\left(1 / q_{D}\right)^{\prime}\right]_{L}=1.77 \pi\left(t_{D} / C_{f D}^{2}\right)_{L}^{0.5}$

Replacing Eqs. 7 and 12 allows to solve for an expression to find fracture conductivity,

$k_{f} w_{f}=\frac{4.034 q \mu B}{h\left[t *(1 / q)^{\prime}\right]_{L}} \sqrt{\frac{\mathrm{kt}_{L}}{\phi \mu c_{t}}}$

Integration of Eq. 56 leads to find the governing expression for the reciprocal rate,

$\left(1 / q_{D}\right)_{L}=1.12 \pi\left(t_{D} / C_{f D}^{2}\right)_{L}^{0.5}$

After replacing Eqs. 7 and 11 and solving for the fracture conductivity from the resulting replacement leads to,
Fig. 6 Unified reciprocal rate derivative versus dimensionless time divided by the dimensionless fracture conductivity squared observed during early linear flow regime

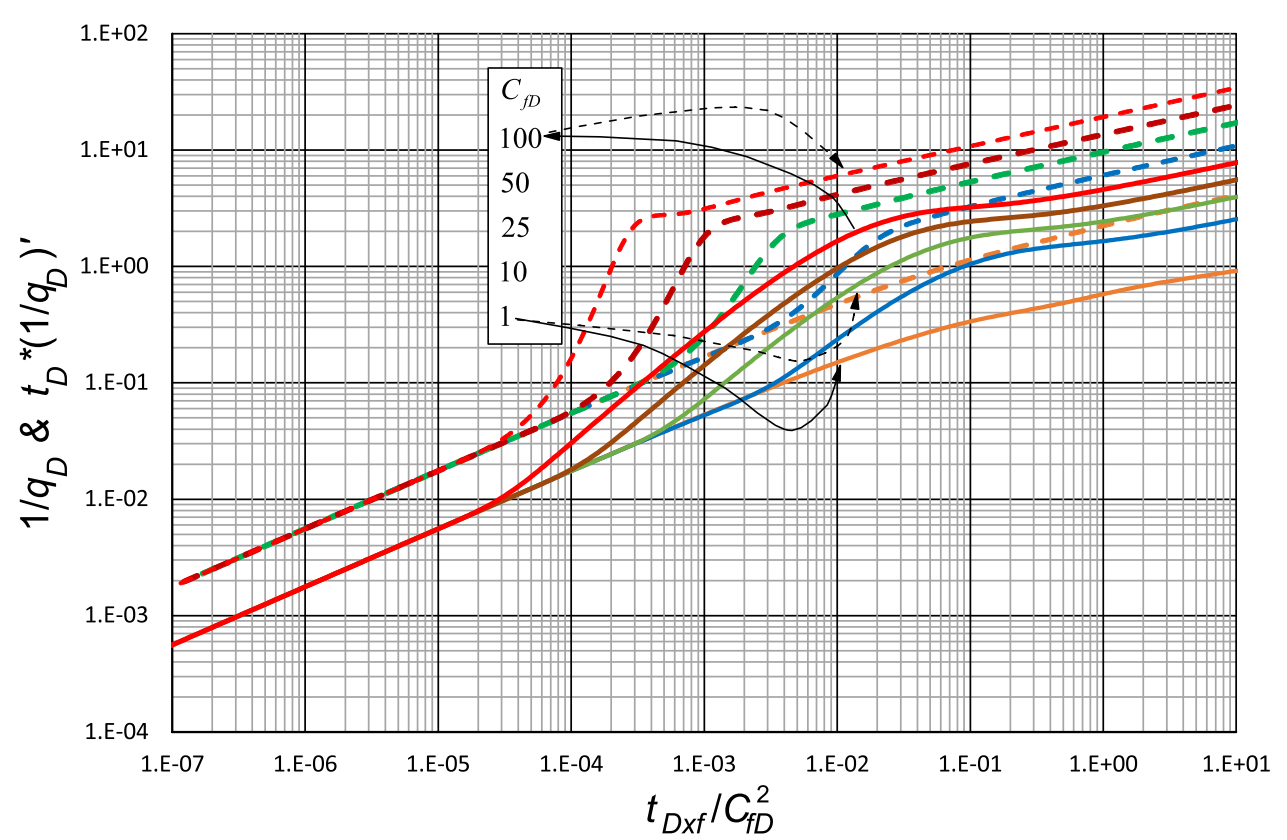


Fig. 7 Unified reciprocal rate derivative versus dimensionless time divided by dimensionless fracture conductivity observed unit-slope behavior

Fig. 8 Unified reciprocal rate versus dimensionless time divided by the square root of dimensionless fractured conductivity both raised squared, observed during the unit-slope behavior of the reciprocal rate derivative
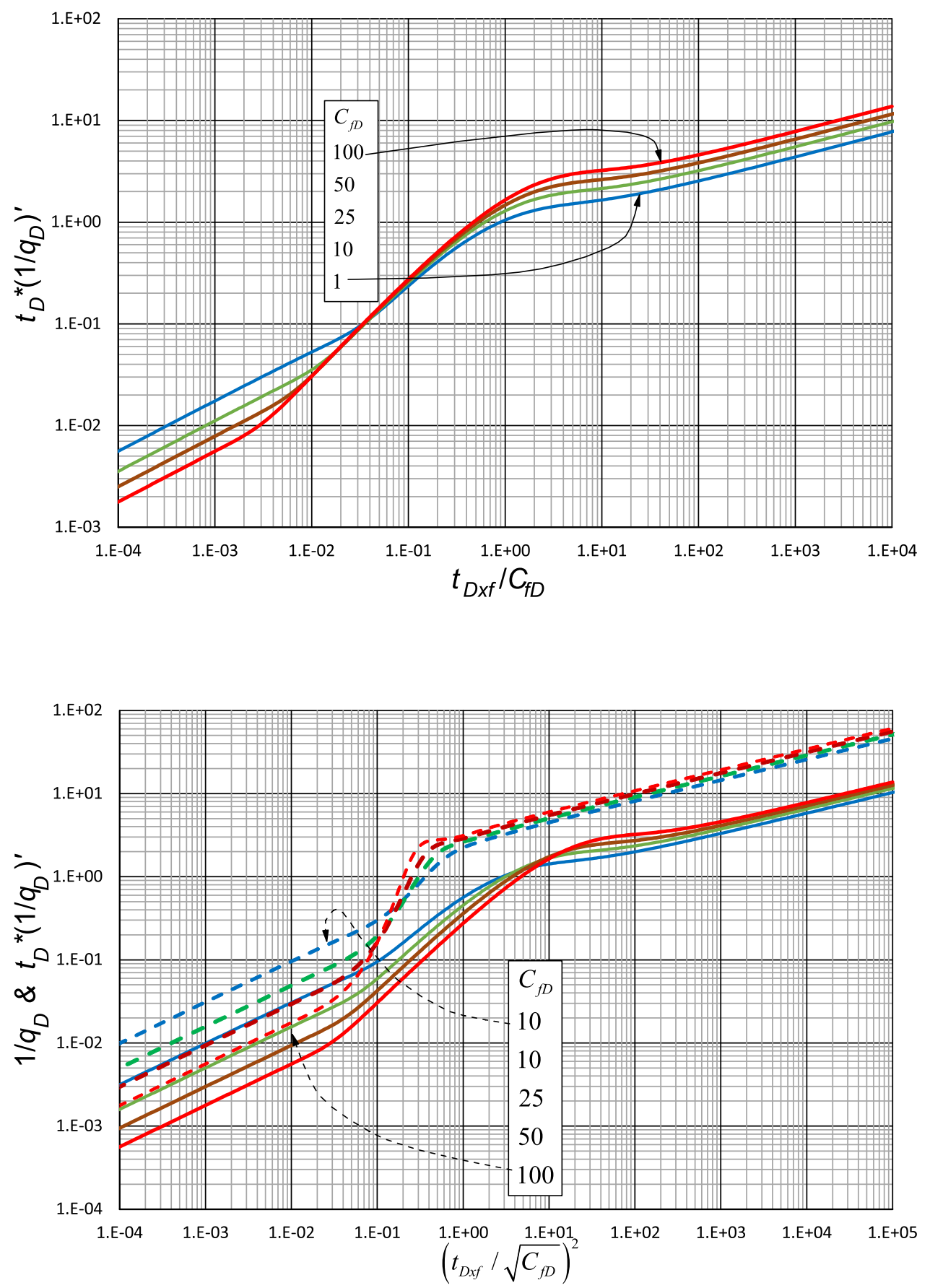

$k_{f} w_{f}=\frac{12.75 \mu B}{h \Delta P(1 / q)_{L}} \sqrt{\frac{\mathrm{kt}_{L}}{\phi \mu c_{t}}}$

Also, another unified reciprocal rate derivative behavior is given in Figs. 7 and 8 from which can be written:

$\left[t_{D} *\left(1 / q_{D}\right)^{\prime}\right]_{U S}=0.9 \pi\left(t_{D} / C_{f D}\right)$
Which also provides an expression for the estimation of the half-fracture length once Eqs. 7 and 12 are replaced in the above equation. Therefore,

$x_{f}=\frac{0.1053 q \mathrm{Bk}}{\phi c_{t} h k_{f} w_{f}}\left(\frac{t}{\left[t *(1 / q)^{\prime}\right]}\right)_{\mathrm{US}}$ 
It is observed during the unit-slope behavior that the reciprocal rate does not follow a unit slope, then the Equation for this was found to be,

$\left.\left(1 / q_{D}\right)\right]_{\mathrm{US}}=\frac{1.8772\left(t_{D}^{2}\right)_{\mathrm{US}}}{\sqrt{C_{f D}}}$

It should be used only if the log-log slope of the reciprocal rate is about 2. From where an expression to find the half-fracture length is found once the dimensionless quantities have been replaced in the above equation,

$x_{f}=\frac{1}{37.86} \sqrt[3]{\left(\frac{\mu B}{k h(\Delta P) k_{f} w_{f}(1 / q)_{\mathrm{US}}}\right)\left(\frac{k t_{\mathrm{US}}}{\phi \mu c_{t}}\right)^{2}}$

A unified behavior is also found during the bilinear flow regime in Fig. 3. The governing expression for this flow regime is given by:

$\left[t_{D} *\left(1 / q_{D}\right)^{\prime}\right]_{\mathrm{BL}}=0.43414\left(t_{D x f}^{0.25}\right)_{\mathrm{BL}}$

An expression to find the half-fractured length is obtained once the dimensionless time, Eq. 7, and dimensionless reciprocal rate derivative, Eq. 12, are plugged in Eq. 64, therefore:

$x_{f}=61.02\left(\frac{\mu B}{\mathrm{kh} \Delta P\left[t *(1 / q)^{\prime}\right]_{\mathrm{BL}}}\right)^{2} \sqrt{\frac{k t_{\mathrm{BL}}}{\phi \mu c_{t}}}$

Or,

$k=15.5\left(\frac{\mu B}{\mathrm{kh} \Delta P\left[t *(1 / q)^{\prime}\right]_{\mathrm{BL}}}\right)^{4 / 3}\left(\frac{t_{\mathrm{BL}}}{\phi \mu c_{t}}\right)^{1 / 3}$

Integrating Eq. 64 results in,

$\left(1 / q_{D}\right)_{B L}=1.736554\left(t_{D x f}^{0.25}\right)_{B L}+c$

Again, the constant, $c$, has no effect in this work. Replacing Eqs. 7 and 11 in the above expression leads to find either:

$x_{f}=976.35\left(\frac{\mu B}{k h \Delta P(1 / q)_{B L}}\right)^{2} \sqrt{\frac{k t_{B L}}{\phi \mu c_{t}}}$

Or,

$k=98.417\left(\frac{\mu B}{k h \Delta P\left(1 / q_{\mathrm{BL}}\right)}\right)^{4 / 3}\left(\frac{t_{\mathrm{BL}}}{\phi \mu c_{t}}\right)^{1 / 3}$

\section{Rate transient analysis by the conventional method for oil reservoirs}

Equation 58 can be rewritten as:
$1 / q=\frac{12.75 \mu B}{h \Delta P k_{f} w_{f}} \sqrt{\frac{k}{\phi \mu c_{t}}} \sqrt{t}$

Which can be expressed as:

$\frac{1}{q}=m_{L} \sqrt{t}$

A Cartesian plot of $1 / q$ vs. $t^{0.5}$ yields a straight line which slope, $m_{L}$, provides the fracture conductivity,

$m_{L}=\frac{12.75 \mu B}{h \Delta P k_{f} w_{f}} \sqrt{\frac{k}{\phi \mu c_{t}}}$

Therefore,

$k_{f} w_{f}=\frac{12.75 \mu B}{h \Delta P m_{L}} \sqrt{\frac{k}{\phi \mu c_{t}}}$

Once the dimensionless parameters have been replaced into Eq. 62 , this be written as:

$(1 / q)=\frac{1}{54255.27}\left(\frac{\mu B}{\phi c_{t} h(\Delta P) k_{f} w_{f} x_{f}^{3}}\right)\left(\frac{k}{\phi \mu c_{t}}\right)^{2} t^{2}$

Or,

$\frac{1}{q}=m_{\mathrm{US}} t^{2}$

A Cartesian plot of $1 / q$ vs. $t^{2}$ yields a straight line which slope, $m_{U S}$, provides the half fracture length,

$x_{f}=\frac{1}{37.86} \sqrt[3]{\left(\frac{\mu B}{\phi c_{t} h(\Delta P) k_{f} w_{f} m_{\mathrm{US}}}\right)\left(\frac{k}{\phi \mu c_{t}}\right)^{2}}$

Equation 67 is rewritten as:

$\frac{1}{q}=31.247 \frac{\mu B}{\mathrm{kh} \Delta P} \sqrt[4]{\frac{k}{\phi \mu c_{t} x_{f}^{2}}} \sqrt[4]{t}$

Or,

$\frac{1}{q}=m_{\mathrm{BL}} \sqrt[4]{t}$

A Cartesian plot of $1 / q$ vs. $t^{0.25}$ yields a straight line which slope, $m_{B L}$, provides the half fracture length,

$x_{f}=31.247\left(\frac{\mu B}{k h \Delta P m_{\mathrm{BL}}}\right)^{2} \sqrt{\frac{k}{\phi \mu c_{t}}}$ 


\section{Transient rate analysis by the TDS technique for gas reservoirs}

Equations 56, 58, 60, 62,64 y 67also work for gas reservoirs. Now, the reciprocal rate and reciprocal rate derivative are affected by pseudopressure instead of pressure and Eqs. 16 and 17 are employed instead of Eqs. 11 and 12. Under these circumstances the resulting equations are:

$k_{f} w_{f}=\frac{40.69 T}{h[\Delta m(P)]\left[t *(1 / q)^{\prime}\right]_{L}} \sqrt{\frac{\mathrm{kt}_{L}}{\phi \mu c_{t}}}$

$k_{f} w_{f}=\frac{81.36 T}{\mathrm{kh}[\Delta m(P)](1 / q)_{L}} \sqrt{\frac{\mathrm{kt}_{L}}{\phi \mu c_{t}}}$

$x_{f}=\frac{1.062 k T t_{\mathrm{US}}}{\phi \mu c_{t} h[\Delta m(P)] k_{f} w_{f}\left[t *(1 / q)^{\prime}\right]_{\mathrm{US}}}$

$k_{f} w_{f}=\frac{T}{34460.6 k h[\Delta m(P)])(1 / q)_{\mathrm{US}}}\left(\frac{k t_{\mathrm{US}}}{\phi \mu c_{t}}\right)^{2}$

$x_{f}=6208.565\left(\frac{T}{k h \Delta m(P)\left[t *(1 / q)^{\prime}\right]_{B L}}\right)^{2} \sqrt{\frac{k t_{B L}}{\phi\left(\mu c_{t}\right)_{i}}}$

Or,

$k=337.8\left(\frac{T}{\mathrm{kh} \Delta m(P)\left[t *(1 / q)^{\prime}\right]_{\mathrm{BL}}}\right)^{4 / 3}\left(\frac{\mathrm{kt}_{\mathrm{BL}}}{\phi\left(\mu c_{t}\right)_{i} x_{f}^{2}}\right)^{1 / 3}$

Or,

$k=2144.915\left(\frac{T}{\operatorname{kh} \Delta m(P)(1 / q)_{\mathrm{BL}}}\right)^{4 / 3}\left(\frac{k t_{\mathrm{BL}}}{\phi\left(\mu c_{t}\right)_{i} x_{f}^{2}}\right)^{1 / 3}$

Intersection points also play an important role in rate transient analysis when the TDS Technique is applied. The following expressions resulted from the reciprocal rate derivative intersection points between the different flow regimes:

$x_{f}=\frac{1}{48.576} \sqrt{\frac{\mathrm{kt}_{L U S i}}{\phi \mu c_{t}}}$

$k=1.697 \sqrt[5]{\frac{\phi \mu c_{t}\left(k_{f} w_{f}\right)^{4}}{x_{f}^{2} t_{L B L i}}}$ $k=11.7166 \sqrt[7]{\left(\frac{\phi \mu c_{t}}{t_{U S B L i}}\right)^{3} x_{f}^{2}\left(k_{f} w_{f}\right)^{4}}$

$k=6.741 \sqrt[3]{\frac{\phi \mu c_{t}\left(k_{f} w_{f}\right)^{2}}{t_{L R i}}}$

$k=\frac{670.606 \phi \mu c_{t} k_{f} w_{f} x_{f}}{t_{U S R i}}$

$x_{f}=\frac{1}{81.6822} \sqrt{\frac{k t_{B L R i}}{\phi \mu c_{t}}}$

Equations 87-92 apply to either oil or gas wells.

\section{Transient rate analysis by the conventional method for gas reservoirs}

Equation 58 can be rewritten as:

$1 / q_{D}=1.12 \pi \sqrt{\frac{t_{D}}{C_{f D}^{2}}}$

$1 / q=\frac{81.36 T}{k h[\Delta m(P)] k_{f} w_{f}} \sqrt{\frac{k}{\phi \mu c_{t}}} \sqrt{t}$

Which can be expressed as Eq. 71 . A Cartesian plot of $1 / q$ vs. $t^{0.5}$ yields a straight line which slope, $m_{L}$, provides the fracture conductivity,

$k_{f} w_{f}=\frac{81.36 T}{\mathrm{kh}[\Delta m(P)] m_{\mathrm{BL}}} \sqrt{\frac{k}{\phi \mu c_{t}}}$

Once the dimensionless parameters have been replaced into Eq. 62, this be written as:

$\frac{1}{q_{\mathrm{sc}}}=\frac{T}{5378.824 \mathrm{kh}[\Delta m(P)] k_{f} w_{f}}\left(\frac{k}{\phi \mu c_{t}}\right)^{2} t^{2}$

Or,

$\frac{1}{q}=m_{\mathrm{US}} t$

A Cartesian plot of $1 / q$ vs. $t^{2}$ yields a straight line which slope, $m_{U S}$, provides the half fracture length,

$k_{f} w_{f}=\frac{T}{5378.824 \mathrm{kh}[\Delta m(P)] m_{\mathrm{US}}}\left(\frac{k}{\phi \mu c_{t}}\right)^{2}$

Equation 67 is rewritten as: 
$\frac{1}{q}=\frac{315.18 T}{\mathrm{kh}[\Delta m(P)]} \sqrt[4]{\frac{k}{\phi\left(\mu c_{t}\right)_{i} x_{f}^{2}}} \sqrt[4]{t_{\mathrm{BL}}}$

Which can be written as Eq. 78. A Cartesian plot of $1 / q$ vs. $t^{0.25}$ yields a straight line which slope, $m_{B L}$, provides the half fracture length,

$x_{f}=99337.95\left(\frac{T}{k h[\Delta m(P)] m_{B L}}\right)^{2} \sqrt{\frac{k}{\phi\left(\mu c_{t}\right)_{i}}}$

From Eq. 53, Tiab (1995), found an expression to find reservoir permeability,

$k=\frac{70.6 q \mu B}{h\left(t * \Delta P^{\prime}\right)_{r}}$
For gas wells,

$$
k=\frac{711,26 q T}{h\left[t_{a}(p) * \Delta m^{\prime}(p)\right]_{r}}
$$

According to Tiab (1995) the mechanical skin factor can be found from:

$S_{m}=0.5\left(\frac{\Delta P_{r}}{\left(t * \Delta P^{\prime}\right)_{r}}-\ln \left[\frac{k t_{r}}{\phi \mu c_{t} r_{w}^{2}}\right]+7.43\right)$

Or for gas wells, the apparent skin factor is given by Escobar,

$S_{m}^{\prime}=0.5\left[\frac{(\Delta m(P))_{r}}{\left[t * \Delta m(P)^{\prime}\right]_{r}}-\ln \left(\frac{\mathrm{kt}_{r}}{\phi\left(\mu c_{t}\right)_{i} r_{w}^{2}}\right)+7.4316\right]$
Table 1 Input data for worked examples

Fig. 9 Pressure and pressure derivative versus time $\log -\log$ plot for synthetic example 1

\begin{tabular}{llll}
\hline Parameter & Synthetic Example 1 & Synthetic Example 2 & Field example \\
\hline$P_{i}, \mathrm{psi}$ & & & 2394 \\
$\Delta m(P), \mathrm{psi}^{2} / \mathrm{cp}$ & & & $3.96 \times 10^{8}$ \\
$T,{ }^{\circ} \mathrm{R}$ & & & 720 \\
$h, \mathrm{ft}$ & 42 & 36 & 32 \\
$\phi, \%$ & 8 & 7 & 10.7 \\
$k, \mathrm{md}$ & 0.76 & 0.15 & 0.0081 \\
$q, \mathrm{BPB}$ & 101 & 250 & \\
$B, \mathrm{rb} / \mathrm{STB}$ & 1.507 & 1.1 & \\
$\mu, \mathrm{cp}$ & 0.45 & 0.74 & 0.0176 \\
$c_{t}, 1 / \mathrm{psi}$ & $1.77 \times 10^{-5}$ & $1.6 \times 10^{-6}$ & $2.34 \times 10^{-4}$ \\
$x_{f}, \mathrm{ft}$ & 79 & 85 & 727 \\
$k_{f} w_{f}, \mathrm{md}-\mathrm{ft}$ & 5403 & 1657.5 & 294 \\
\hline
\end{tabular}

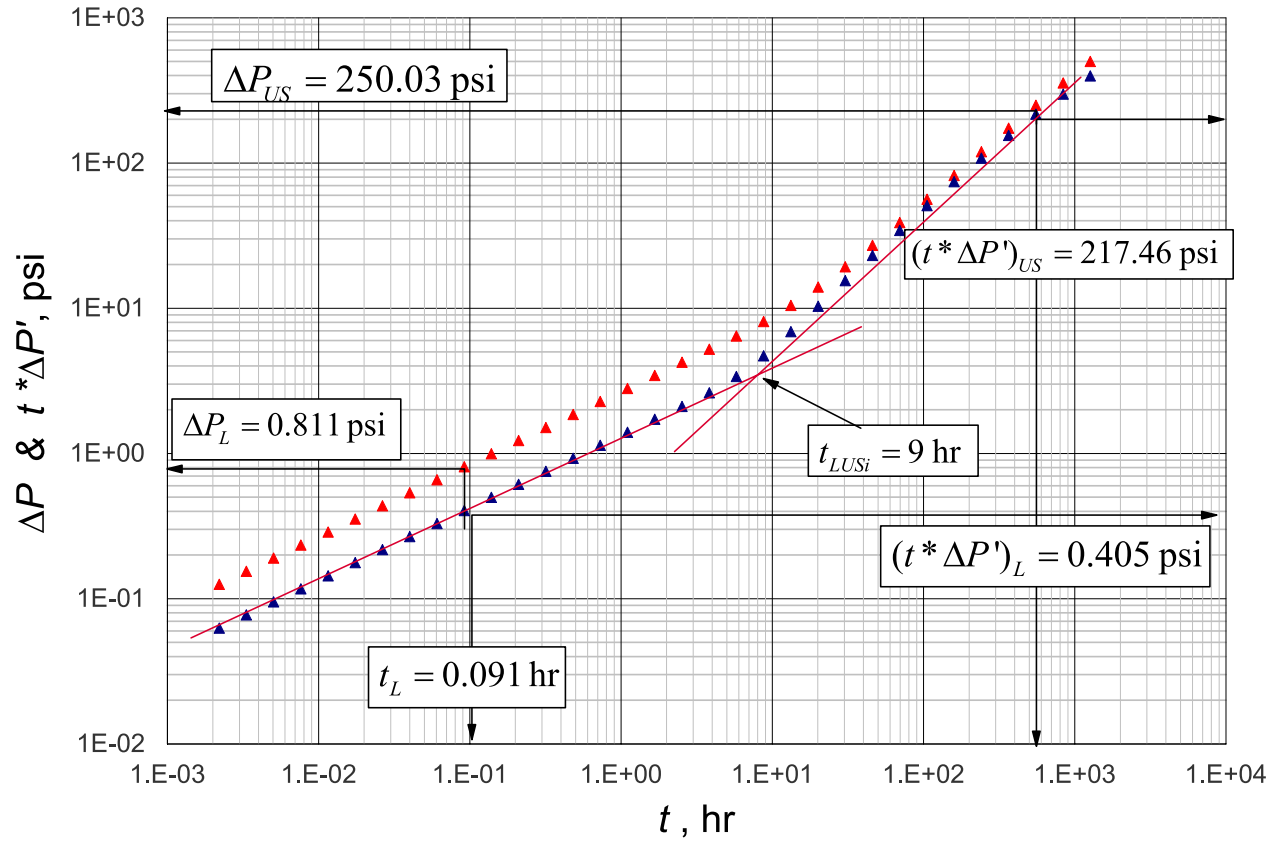


Escobar et al. (2016) presented a couple of expressions to find the mechanical skin factor when radial flow regime is absent. Also, a correlation to find half-fractured length as a function of fracture conductivity of vice versa.

\section{Data interpretation}

\section{Example 1: Synthetic example}

The second column of Table 1 presents the input data used to generate the simulated drawdown reported in Fig. 9.

\section{TDS Technique}

From Fig. 9 the following information was read:

$$
\begin{aligned}
& t_{L}=0.091 h \Delta P_{L}=0.811 p s i\left(t * \Delta P^{\prime}\right)_{L}=0.405 p s i \\
& t_{U S}=552.84 h \Delta P_{U S}=250.03 p s i\left(t * \Delta P^{\prime}\right)_{U S}=217.46 \mathrm{psi} \\
& t_{L U S i}=9 h
\end{aligned}
$$

The linear flow regime was used to calculate the fracture conductivity by means of Eq. 19 and 21 using pressure derivative and pressure data, respectively: $k_{f} w_{f}=\frac{4.3(101)(0.45)(1.507)}{(42)(0.405)}$

$\sqrt{\frac{0.76(0.091)}{0.08(0.45)\left(1.77 \times 10^{-5}\right)}}=5704.3 \mathrm{md}-\mathrm{ft}$

$k_{f} w_{f}=\frac{8.6(101)(0.45)(1.507)}{(42)(0.811)}$

$\sqrt{\frac{0.76(0.091)}{0.08(0.45)\left(1.77 \times 10^{-5}\right)}}=5697.25 \mathrm{md}-\mathrm{ft}$

The half-fracture length is then found from the unit-slope trend on the pressure derivative curve by using Eq. 24 and 25 ,

$x_{f}=\frac{0.1(101)(0.76)(1.507)}{(42)(0.08)\left(1.77 \times 10^{-5}\right)(6209.7)}\left(\frac{552.84}{217.46}\right)=86.7 \mathrm{ft}$

Use of Eq. 49 leads to verify the half-fracture length:

$x_{f}=\frac{1}{41.054} \sqrt{\frac{0.76(9)}{0.08(0.45)\left(1.77 \times 10^{-5}\right)}}=79.8 \mathrm{ft}$

\section{Conventional analysis}

Figures 10 and 11 present Cartesian plots from which the slope of the linear flow regime, $m_{L}$, and the unit-slope behavior, $m_{U S}$, were found to be:
Fig. 10 Cartesian plot of pressure drop versus the square root of time for synthetic example 1

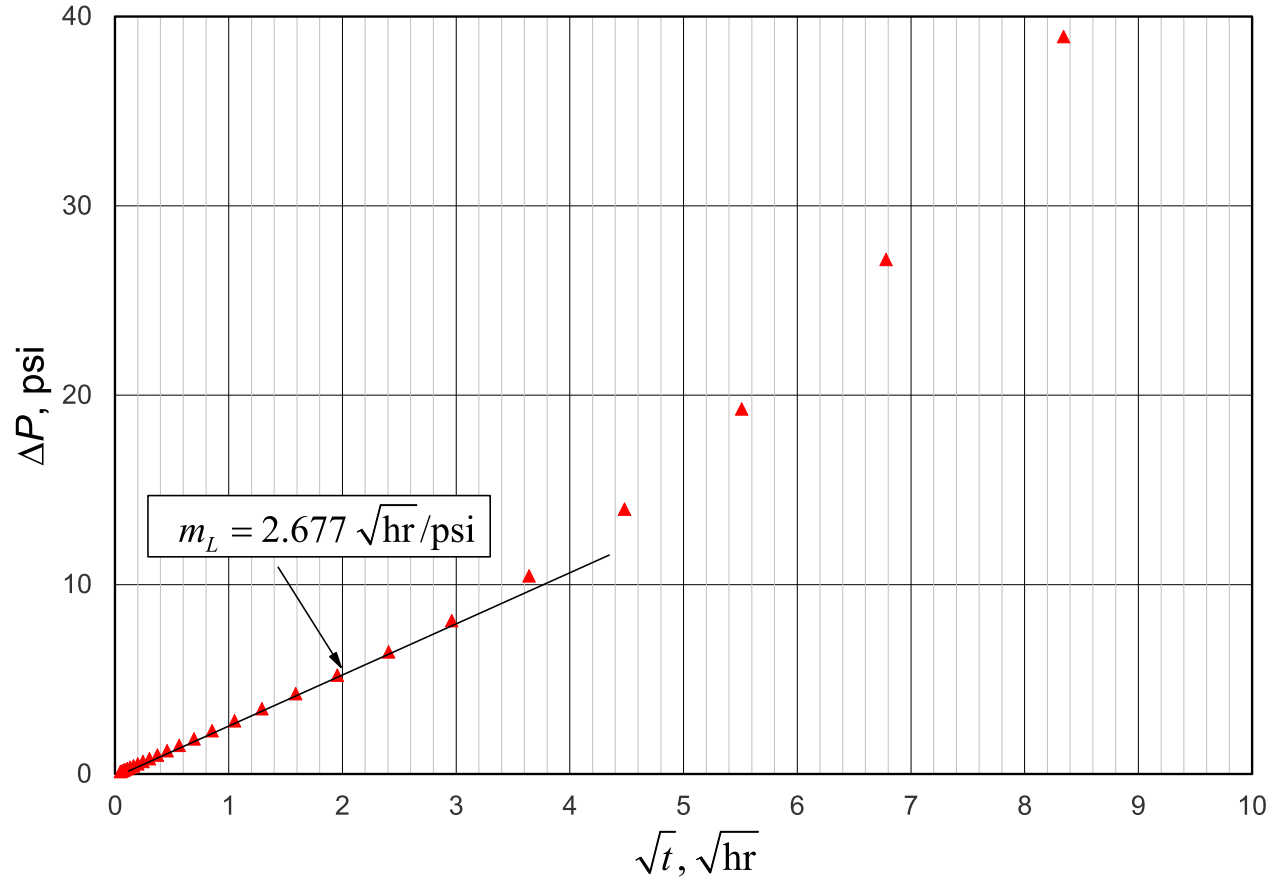


Fig. 11 Cartesian plot of pressure drop versus time for synthetic example 1

$$
\begin{gathered}
x_{f}=\frac{0.1(101)(0.76)(1.507)}{(42)(0.08)\left(1.77 \times 10^{-5}\right)(6209.7)}\left(\frac{552.84}{250.03}\right)=75.5 \mathrm{ft} \\
m_{L}=2.677 \mathrm{hr}^{0.5} / \mathrm{psi} \text { and } m_{U S}=0.3229 \mathrm{~h} / \mathrm{psi} . \text { Use of }
\end{gathered}
$$
Eqs. 33 and 37 allows finding the fracture conductivity,

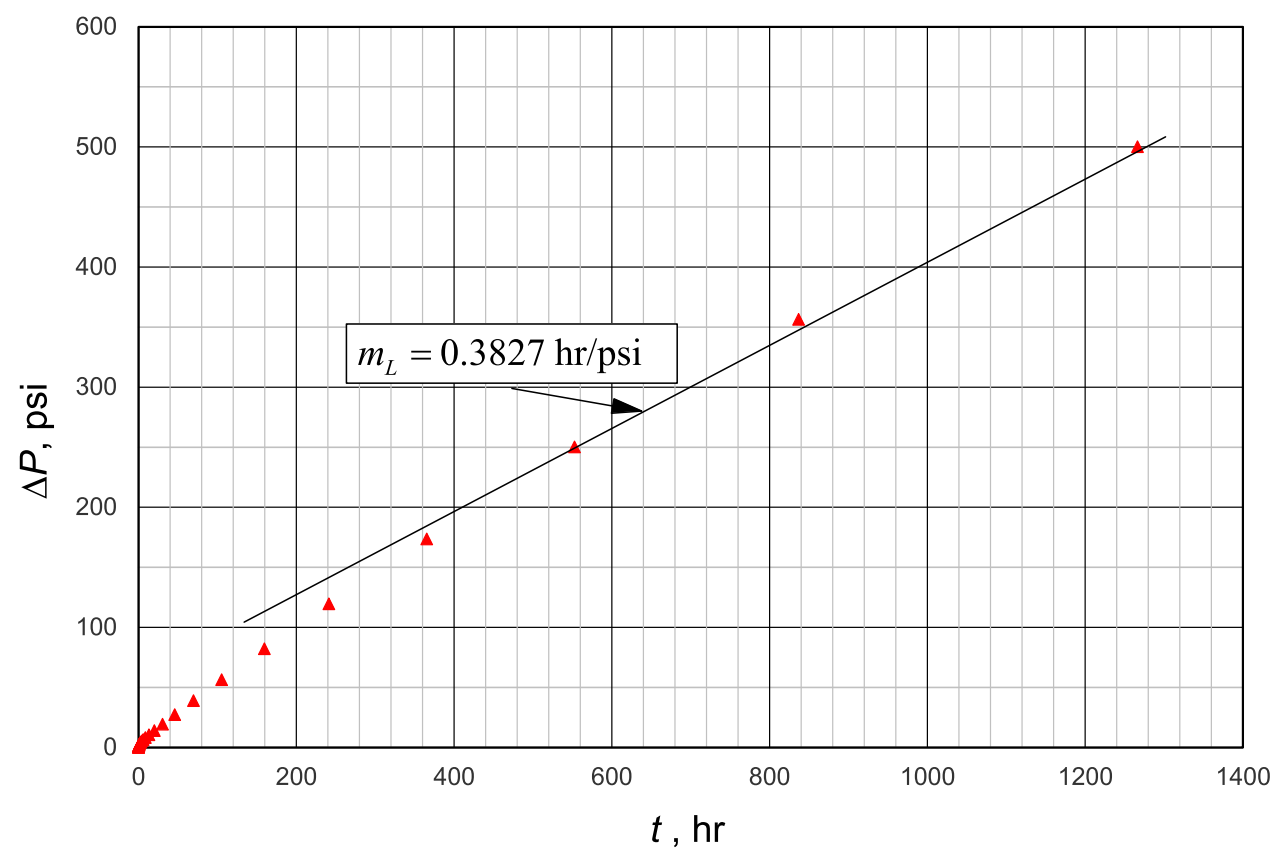

Fig. 12 Reciprocal rate and reciprocal rate derivative versus time $\log -\log$ plot for synthetic example 2

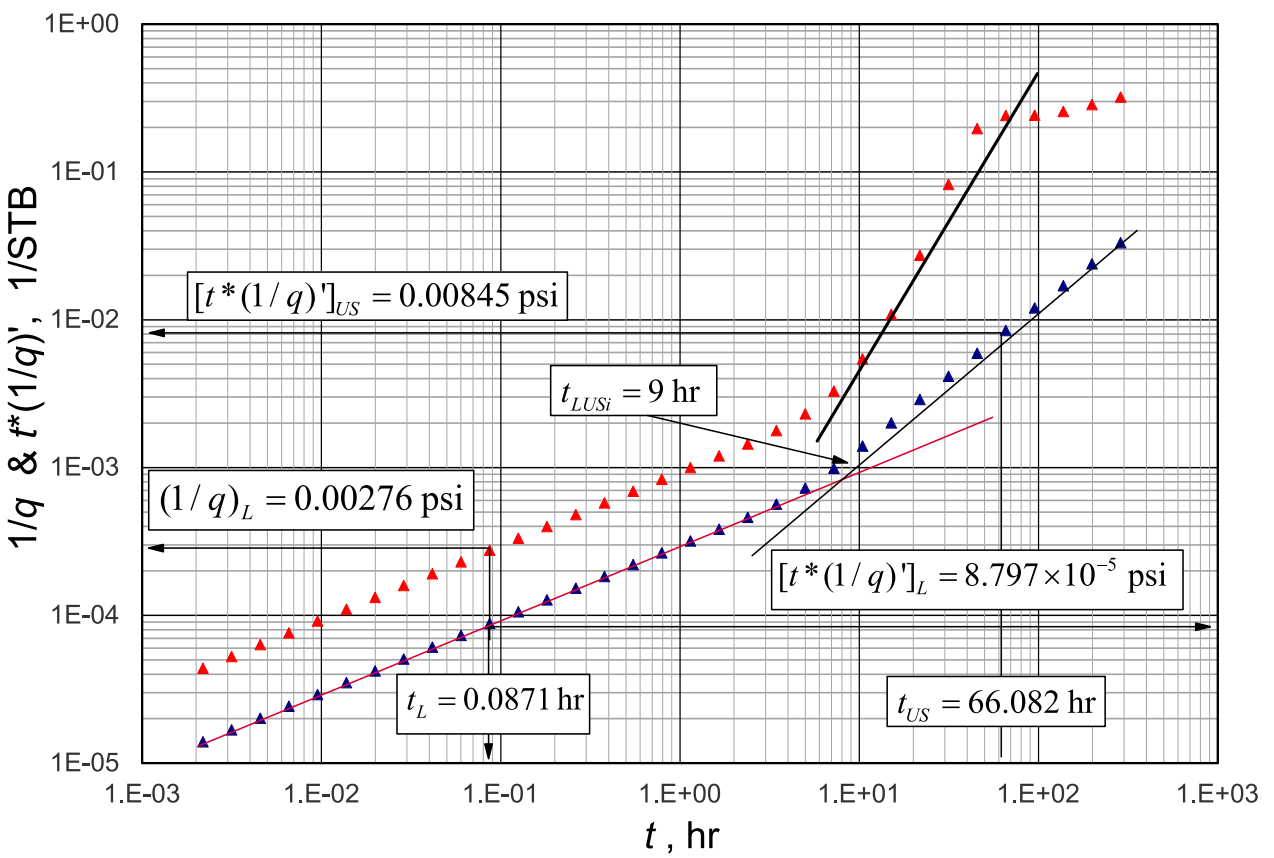

$x_{f}=\frac{0.1(101)(1.507)(0.76)}{(42)(0.08)\left(1.77 \times 10^{-5}\right)(5403)(0.3286)}=94 \mathrm{ft}$ 


\section{Example 2: Synthetic example}

The third column of Table 1 were used to generate the reciprocal rate and reciprocal rate derivative data presented in Fig. 12.

Solution to this problem has two limitations which can be drawn from Fig. 12. During the unit-slope behavior the slope of the reciprocal rate is different than 2.0, therefore it is not recommended to use conventional analysis, Eq. 67 nor TDS Technique with the reciprocal rate value Eq. 63. Conventional analysis will only be applied to the linear flow regime.

\section{TDS Technique}

The following information was read from Fig. 12.

$t_{L}=0.0871 h(1 / q)_{L}=0.002761 / S T B$

$\left[t *(1 / q)^{\prime}\right]_{L}=0.000087971 / S T B t_{L U S i}=9 h$

$t_{U S}=66.082 h\left[t *(1 / q)^{\prime}\right]_{U S}=0.008451 / S T B$

From the linear flow regime fracture conductivity was estimated using Eq. 57 and 59 to be $1646.7 \mathrm{md}-\mathrm{ft}$ and $1657.92 \mathrm{md}-\mathrm{ft}$ respectively, as indicated below: $k_{f} w_{f}=\frac{4.034(250)(0.74)(1.1)}{(36)(0.00008797)}$

$\sqrt{\frac{0.15(0.0871)}{(0.07)(0.74)\left(1.6 \times 10^{-6}\right)}}=1646.7 \mathrm{md}-\mathrm{ft}$

$k_{f} w_{f}=\frac{12.75(250)(0.74)(1.1)}{(36)(0.00845)}$

$\sqrt{\frac{0.15(0.0871)}{(0.07)(0.74)\left(1.6 \times 10^{-6}\right)}}=1657.9 \mathrm{md}-\mathrm{ft}$

The reciprocal rate derivative during the unit-slope behavior was used to find the half-fracture length with Eq. 61 to be $81.9 \mathrm{ft}$.

$x_{f}=\frac{0.1053(250)(0.15)(1.1)}{(36)(0.07)\left(1.6 \times 10^{-6}\right)(1616.8)}\left(\frac{66.082}{0.00845}\right)=81.9 \mathrm{ft}$

Also, Eq. 87 allows us to verify the half-fracture length:

$x_{f}=\frac{1}{48.576} \sqrt{\frac{0.15(9)}{(0.07)(0.74)\left(1.6 \times 10^{-6}\right)}}=83.1 \mathrm{ft}$

\section{Conventional analysis}

As commented previously, conventional analysis was applied only to the linear flow regime. A Cartesian plot of the reciprocal rate versus the square root of time is shown in Fig. 13 which slope $m_{L}=0.0009336 \mathrm{hr}^{0.5} / \mathrm{STB}$. With this the fracture conductivity is computed with Eq. 73 to be $1661.76 \mathrm{md}-\mathrm{ft}$.
Fig. 13 Cartesian plot of the reciprocal rate versus the square root of time for synthetic example 2

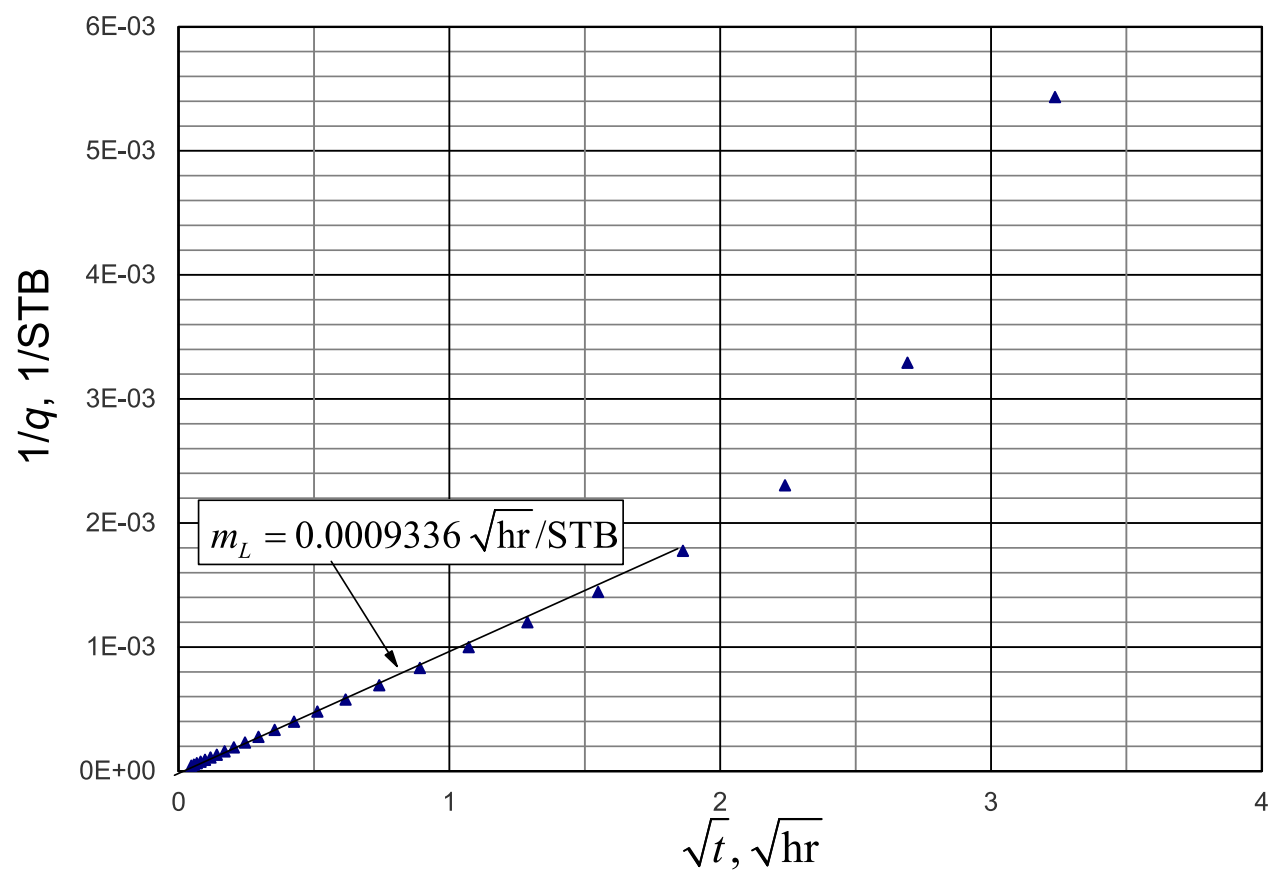


Table 2 Input data for worked examples

\begin{tabular}{lll}
\hline$t, \mathrm{hr}$ & $1 / q, \mathrm{D} / \mathrm{Mscf}$ & $t^{*}(1 / q)^{\prime}, \mathrm{D} / \mathrm{Mscf}\left(^{*}\right)$ \\
\hline 480 & 0.00160 & 0.001112 \\
840 & 0.00210 & 0.000986 \\
1200 & 0.00245 & 0.000974 \\
2400 & 0.00325 & 0.001549 \\
3600 & 0.00400 & 0.001712 \\
6000 & 0.00481 & 0.002014 \\
7200 & 0.00521 & 0.002408 \\
\hline
\end{tabular}

(*) Estimated in this work

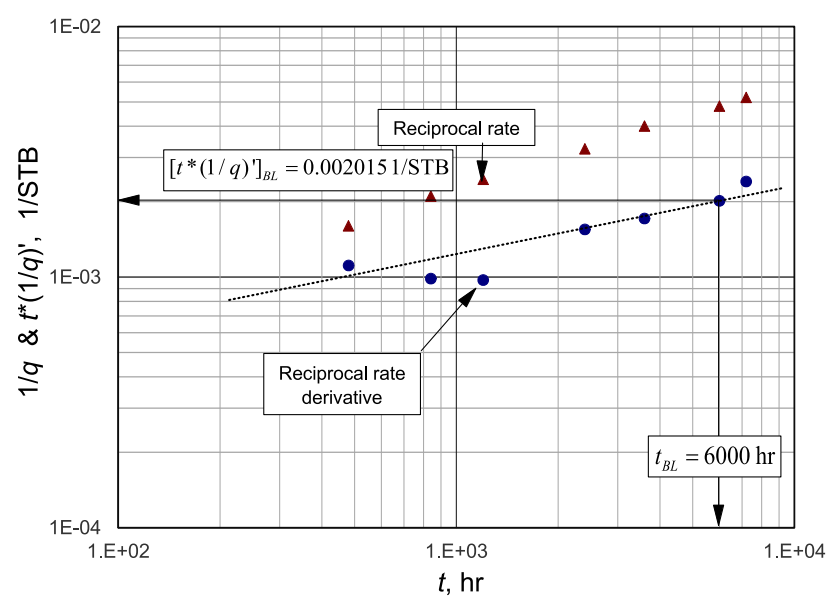

Fig. 14 Reciprocal rate and reciprocal rate derivative versus time for field example

$k_{f} w_{f}=\frac{12.75(250)(0.74)(1.1)}{(36)(0.0009336)}$

$\sqrt{\frac{0.15}{(0.07)(0.74)\left(1.6 \times 10^{-6}\right)}}=1661.8 \mathrm{md}-\mathrm{ft}$

\section{Example 3: Field example}

The fourth column of Table 1 presents information of a massive hydraulically fractured gas well reported by Agarwal, Carter, and Pollock (1979) which time and reciprocal rate are given in Table 2. The reciprocal rate derivative was estimated in this work and it is also reported in Table 2.

\section{TDS technique}

The reciprocal rate and reciprocal rate derivative versus time $\log -\log$ plot is provided in Fig. 14. Only bilinear flow is observed and the following information is obtained from there:

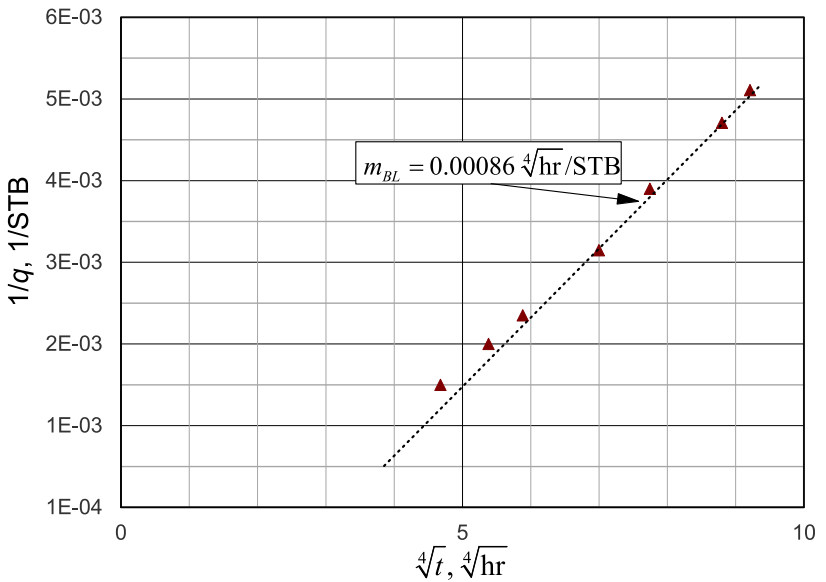

Fig. 15 Reciprocal rate versus the fourth root of time for field example (conventional analysis)

Table 3 Summary of results

\begin{tabular}{llll}
\hline Parameter & Value & Eq & Abs. Error, \% \\
\hline Synthetic example 1 & & & \\
$x_{f}, \mathrm{ft}$ & 86.7 & 24 & 9.73 \\
$x_{f}, \mathrm{ft}$ & 79.8 & 49 & 1.02 \\
$k_{f} w_{f}$, md-ft & 5704.3 & 19 & 5.58 \\
$k_{f} w_{f}$, md-ft(*) & 5721.52 & 33 & 5.90 \\
ejemplo 2 & & & \\
Synthetic example 2 & & & \\
$x_{f}, \mathrm{ft}$ & 81.9 & 61 & 3.70 \\
$x_{f}, \mathrm{ft}$ & 83.1 & 87 & 2.25 \\
$k_{f} w_{f}$, md-ft & 1646.7 & 57 & 0.65 \\
$k_{f} w_{f}$, md-ft & 1657.9 & 59 & $0.03 \%$ \\
$k_{f} w_{f}$, md-ft(*) & 1661.8 & 73 & $0.26 \%$ \\
Field Example & & & \\
$x_{f}, \mathrm{ft}$ & 790.15 & 84 & $7.99 \%$ \\
$x_{f}, \mathrm{ft}(*)$ & 896 & 100 & $18.86 \%$ \\
\hline
\end{tabular}

(*) Conventional analysis

$t_{\mathrm{BL}}=6000 \mathrm{hr}\left[t *(1 / q)^{\prime}\right]_{\mathrm{BL}}=0.0020141 / \mathrm{STB}$

Reciprocal rate value during bilinear time is not read since the difference between the reciprocal rate derivative and the reciprocal rate derivative has a difference less than 4 units. Use of Eq. 84 allows to find the half-fracture length:

$x_{f}=6208.565\left(\frac{720}{0.0081(32)\left(3.96 \times 10^{8}\right)[0.002015]}\right)^{2}$

$\sqrt{\frac{0.0081(6000)}{0.107(0.0176)\left(2.34 \times 10^{-4}\right)}}=790.15 \mathrm{ft}$ 


\section{Conventional analysis}

The Cartesian plot of the reciprocal rate versus the fourth root of time are given versus time is given in Fig. 15. The slope of this plot:

$m_{\mathrm{BL}}=0.00086 \mathrm{hr}^{0.25} / \mathrm{STB}$

The half-fracture length is found from Eq. 100 to be,

$$
\begin{aligned}
& x_{f}=99337.95\left(\frac{720}{0.0081(32)\left(3.96 \times 10^{8}\right)(0.00086)}\right)^{2} \\
& \sqrt{\frac{0.0081}{0.107(0.0176)\left(2.34 \times 10^{-4}\right)}}=896 \mathrm{ft}
\end{aligned}
$$

\section{Comments on the results}

Table 3 summarizes the results of the worked examples. As expected, the results obtained from both TDS Technique and conventional analysis are satisfactory with errors ranging from $0.03 \%$ up to almost $10 \%$ for the synthetic examples and error of $8 \%$ for the estimation of the half-fracture length in the actual field case example. However, notice that the value of $x_{f}=727 \mathrm{ft}$ reported in Table 1 was obtained by using type-curve matching which is not the best well test interpretation method.

It is customary to obtain fracture conductivity from the classical bilinear flow regime and half-fracture length from the classical linear flow regime. For our case, the trilinear model, the situation is inverted.

\section{Conclusions}

a) TDS technique has been proven to be accurate and also to be a practical tool for well test analysis. In this case, it is extended to a trilinear flow model in oil and gas hydraulically finite-conductivity fractured wells under both constant-rate and constant-pressure cases. Several equations were developed and successfully tested against synthetic examples and a field case. Also, equations for the conventional analysis method are developed and verified with the mentioned examples. However, for the case of reciprocal rate during the intermediate unit-slope behavior, conventional analysis is not recommended to be applied if the slope of the reciprocal rate versus time $\log -\log$ plot is different than two.

b) The bilinear flow regime and the linear flow regime allow to obtained either half-fracture length and fracture conductivity, respectively. This situation is contrary to the classical bilinear and linear flow regimes.

\section{Ethical Statement}

This manuscript has not be submitted to other journal for simultaneous consideration.

The submitted work is original and has not been published elsewhere in any form or language (partially or in full.

This study is not split up into several parts to increase the quantity of submissions and submitted to various journals or to one journal over time.

Results are presented clearly, honestly, and without fabrication, falsification or inappropriate data manipulation (including image based manipulation). Authors adhere ourselves to discipline-specific rules for acquiring, selecting and processing data.

No data, text, or theories by others are presented as if they were the author's own ('plagiarism'). Proper acknowledgements to other works must be given (this includes material that is closely copied (near verbatim), summarized and/or paraphrased), quotation marks (to indicate words taken from another source) are used for verbatim copying of material, and permissions secured for material that is copyrighted.

Funding The authors thank Universidad Surcolombiana for funding this research.

Open Access This article is licensed under a Creative Commons Attribution 4.0 International License, which permits use, sharing, adaptation, distribution and reproduction in any medium or format, as long as you give appropriate credit to the original author(s) and the source, provide a link to the Creative Commons licence, and indicate if changes were made. The images or other third party material in this article are included in the article's Creative Commons licence, unless indicated otherwise in a credit line to the material. If material is not included in the article's Creative Commons licence and your intended use is not permitted by statutory regulation or exceeds the permitted use, you will need to obtain permission directly from the copyright holder. To view a copy of this licence, visit http://creativecommons.org/licenses/by/4.0/.

\section{References}

Agarwal RG, Carter RD, Pollock CB (1979) Evaluation and performance prediction of low-permeability gas wells stimulated by massive hydraulic fracturing. J Petrol Technol 31:362-372. https://doi.org/10.2118/6838-PA

Cinco LH, Samaniego VF, Dominguez AN (1978) Transient pressure behavior for a well with a finite-conductivity vertical fracture. Soc Petrol Eng. https://doi.org/10.2118/6014-PA

Cinco-Ley H, Samaniego (1981) Transient Pressure Analysis for Fractured Wells. JPT (Sept.). pp. 1479-1766 
Cinco-Ley H (1982) Evaluation of hydraulic fracturing by transient pressure analysis methods. Soc Petrol Eng. https://doi.org/10. 2118/10043-MS

Cossio M, Moridis GJJ, Blasingame TAA (2013) A semianalytic solution for flow in finite-conductivity vertical fractures by use of fractal theory. SPE J 18:83-96. https://doi.org/10.2118/153715-PA

Escobar FH (2015) Recent Advances in Practical Applied Well Test Analysis. Nova publishers New York. Published by Nova Science Publishers, Inc. † New York. 423p. Nov

Escobar FH, Gonzalez RA, Hernandez LM, Hernandez CM (2016) Pressure and pressure derivative analysis for hydraulically fractured vertical wells with face skin. J Eng Appl Sci 11(13):8268-8273

Escobar FH (2019) Novel, Integrated and Revolutionary Well Test Interpretation Analysis. Intech I Open Mind, England. 278p. DOI: http://dx.doi.org/https://doi.org/10.5772/intechopen.81078. ISBN 978-1-78984-850-2 (print). ISBN 978-1-78984-851-9 (online)

Gringarten AC, Ramey HJ, Raghavan R (1974) Unsteady-state pressure distributions created by a well with a single infinite-conductivity vertical fracture. Soc Petrol Eng. https://doi.org/10.2118/4051-PA
Lee ST, Brockenbrough JR (1986) A new approximate analytic solution for finite-conductivity vertical fractures. SPE Form Eval 1:75-88. https://doi.org/10.2118/12013-PA

Tiab D (1995) Analysis of pressure and pressure derivative without type-curve matching: 1- skin and wellbore storage. J Petrol Sci Eng 12:171-181

Tiab D, Azzougen A, Escobar FH, Berumen-Campos S (1999) Analysis of pressure derivative data of finite-conductivity fractures by the "Direct Synthesis" technique. Soc Petrol Eng. https://doi.org/ 10.2118/52201-MS

Tiab D (1994) (1994) Analysis of pressure derivative without type curve matching: vertically fractured wells in closed systems. J Petrol Sci Eng 11:323-333. https://doi.org/10.2118/26138-MS

Wong DW, Harrington AG, Cinco-Ley H (1984) Application of the pressure derivative function in the pressure transient testing of fractured wells. SPEFE 1(5):470-480. https://doi.org/10.2118/ 13056-PA

Publisher's Note Springer Nature remains neutral with regard to jurisdictional claims in published maps and institutional affiliations. 